https://helda.helsinki.fi

\title{
Private equity and the concept of brittle trust
}

\section{Green, Sarah}

\section{2}

Green , S , Froud , J \& Williams , K 2012 , ' Private equity and the concept of brittle trust ' , Sociological Review, vol. 60 , no. 1 , pp. 1-24 .

http://hdl.handle.net/10138/39176

publishedVersion

Downloaded from Helda, University of Helsinki institutional repository.

This is an electronic reprint of the original article.

This reprint may differ from the original in pagination and typographic detail.

Please cite the original version. 


\title{
Private equity and the concept of brittle trust
}

\section{Julie Froud, Sarah Green and Karel Williams}

\begin{abstract}
This paper focuses on private equity in the UK and is set in the context of debates about transformations in the City of London. The article focuses on a particular concept of trust as expressed by senior members of the private equity sector. The argument developed is based on interviews with five senior founding partners of private equity firms who talked to us about their background and education, their understanding of how private equity worked and the basis for successful money making and their relationships with those inside and outside the organization. All interviewees strongly asserted the need for absolute trust between senior partners as an essential condition for the successful operation of their business. At the same time, their description of trust in this context was that while it is deep, it is also easily broken, and that once broken, the breach cannot be forgiven. We call this 'brittle trust': asserted to be simultaneously strong while extremely fragile. The paper argues, drawing on Diego Gambetta's work on the Sicilian Mafia, that this concept of 'trust' reflects a particular understanding of the practice of private equity as a high risk, tough and unforgiving business that nevertheless requires high standards of personal integrity. The study allows us to understand something more about the social ideals that were built into this financial sector by its founders, which we argue formed a crucial part of the transformation of the financial sector.
\end{abstract}

Keywords: Private equity, finance, elites, trust, mafia

\section{Introduction}

Private equity became a public issue in the UK in 2007 when leading firms clashed with trade unions as private equity took over or threatened household name public companies such as Boots and Sainsbury's. In the ensuing media and political controversy, the British Private Equity and Venture Capital Association (BVCA) defended private equity firms as responsible owners against charges of asset stripping and job cuts. The banking crisis of 2007 cut off the flow of private equity deals and shifted public attention to other issues. Yet controversies about private equity have not gone away: the 2011 collapse of Southern Cross care homes has brought private equity practices back under public scrutiny. Here, sale and lease back of properties under previous private 
equity ownership contributed to the financial collapse of the company, with Southern Cross unable to meet its rental costs. Such failure and all the social and political implications associated with that has been put in stark relief by disclosures of the gains made by former directors of the company or by the Blackstone private equity group which bought Southern Cross in 2004, combined it with other care home groups and floated it back on the stock market in $2006 .{ }^{1}$

What was striking about the earlier public debate on private equity was that while it focused on the wider socio-economic effects of the business, little attention was paid to the way private equity firms operated internally whilst they were buying, holding and selling companies and apparently wreaking socio-economic havoc in the process. During the public debates in 2007, private equity opponents raised concerns about financial engineering, job losses, secrecy and the negative effects that PE was apparently having on the wider stability and quality of social and economic relationships (Froud and Williams, 2007). Yet despite high profile public debates between the industry and its critics, including a House of Commons Treasury Select Committee hearing and report (2007), few have studied how those centrally involved in private equity developed the sector and made sense of their own practices and social relations. This paper focuses on that aspect of the private equity phenomenon. Through network contacts in 2008 we arranged to interview five of the founding fathers of British private equity who had all been significant in shaping the private equity sector in the UK since the 1980s. They agreed to talk about operating issues such as the decision-making processes around deals, the qualities of a successful partner, and their sense of what constitutes 'a good life'.

Over time, we narrowed our focus to concepts of trust expressed by these men. They all regularly mentioned that those involved at the top levels of private equity (PE) must adhere to principles that depended heavily upon 'absolute trust' between senior partners. In their accounts, a deep level of trust was required because of the long-term commitment involved in private equity (where fund life is typically ten years), and the notably high financial risks involved. Simultaneously, PE was represented as a brutal business that would not tolerate sub-standard performance: anyone falling short, either in personal integrity or in skills, was to be instantly discarded without exception, and without any regard for notions of loyalty or friendship - and this explicitly included partners of the firm. This combination of an assertion of deep trust that can nevertheless be easily and irrevocably broken invited further questions about the particular understanding of 'trust' that was being evoked in this context, and how that understanding reflected the social principles that informed the development and practice of private equity in the UK. Gillian Tett (2009), in her study of the bankers who developed credit derivatives techniques at J.P. Morgan, shows how a particular social dynamic, informed by distinctive values, relations and attitudes, developed within this part of the banking sector. Tett argues that these social dynamics led to what later turned 
out to be highly inadvisable risk-taking amongst some of the most skilled financial specialists of the period. Our study focuses on the people who helped to create private equity in the UK, and in this paper, we consider how their understanding of trust helped to shape the social dynamics of that sector.

The concept of deep, yet brittle, mutual trust amongst senior PE partners reflects a different, more context-specific, approach from those studies suggesting that there is a cumulative and generalized breakdown of trust in Western social contexts; and it adds to studies looking at diverse forms of trust in different contexts, such as the apparent rise of 'impersonal trust' in the retailing of financial services, where economic transactions are not part of mutual social relations, as Shapiro (1987), amongst others, has discussed. However, we go one step further back in trying to understand both how the evoking of the idea of trust helps to generate a particular kind of social context; and to understand the particular form of trust that is being evoked. It is certainly not the impersonal form Shapiro has discussed; nor is it the kind classically associated with family ties, involving assertions of unbreakable bonds. Our aim is to focus on the distinctive and context-specific way the concept of trust has been evoked within the PE sector, so as to understand something more about the way this sector was imagined, and therefore built, by some of its founders.

Through this focus, our arguments make a contribution to studies of 'new capitalism' in general and the financial sector in particular, many of which argue that there has been an epochal change towards more transactional relations. This implies the decline of a sense of enduring or close social relations: within this view, each encounter with others is treated as an isolated transaction, rather than as part of an ongoing social relationship that involves mutual obligations. This was not borne out by our interviews: all interviewees emphasized the need for long-term relations that demonstrate enduring integrity in interactions with their fellow senior PE partners, even while they simultaneously emphasized that such relations could be destroyed in an instant. This suggested a sense of having to strongly rely on certain people in a high-risk environment; this same risky environment would also both justify and necessitate the jettisoning of those same people if they proved themselves to be even minimally unreliable. In trying to understand this social dynamic, we have looked for other social contexts that are described in a similar way, to examine how and whether the idea of trust was evoked there. The work of Diego Gambetta on the development of Mafia in Sicily and Mafiosi's expressed social principles and ideals provided us with one such comparable, as well as contrastive, example: demands for deep levels of trust and mutual commitment that could be destroyed in an instant also stereotypically characterized that social context.

A discussion of the apparently new social character of 'new capitalism' is introduced in the first section of our paper, before we turn to some of the literature that explicitly discusses trust, particularly in the economic sociology literature. The second section provides context and background on private 
equity as an activity and the uncertain combination of conditions that come together (what we term 'conjunctural' conditions) under which this particular concept of trust has developed. The third section uses interview material to explore relations within PE and develops our central argument about brittle trust. A concluding section inserts our findings into a broader frame and returns to Gambetta to examine the apparent paradox that this strong assertion of absolute trust was accompanied by an equally strong assertion of uncompromising exclusion of anybody who infringed that trust.

\section{Framing: 'new capitalism' in the new City and understanding trust}

Studies of how capitalism has changed in recent years ${ }^{2}$ often discuss trust and its relations with new social relations and moral sensibilities. These studies suggest that trust itself is undergoing change, rather than simply disappearing. As Cook notes, while there is an implicit assumption in much debate that there has been a fundamental weakening of public trust in key political and social institutions, this does not mean that trust has vanished (Cook, 2001: xi). For example, the successful expansion of the financial system through new products requires what Shapiro (1987) terms impersonal trust: the consumer who pays into a pension scheme or takes out an insurance policy can reasonably believe that they will receive the benefits promised when, or if, specific circumstances arise like retirement or accident. Shapiro's point is that trust takes a particular form here: confidence that institutions will pay up is not based on personal relations within the institution, but 'impersonal trust', a faith in mutual compliance with agreements and understandings that may be underwritten, enforced or in some other way protected by the state or other institutions.

This is familiar ground: classical political economists have developed the idea that epochal changes in social relations almost always accompany transformations in economic systems and structures. ${ }^{3}$ In The Culture of the New Capitalism, Richard Sennett (2006) continues this trend by charting what he sees as a fundamental shift in the form that capitalism has taken: a former pyramid-style of hierarchical organization, with its long-term, risk-averse, bureaucratic style has been replaced by flattened, flexible, unstable organizations without any clear borders, which pass responsibility sideways (to management consultants) and downwards (in emphasizing personal autonomy). Companies are controlled not by managers but by short-term investors, and "transactions" have replaced "relationships" in people's dealings with one another' (Sennett, 2006: 25). In doing so, social relations cease to have the long-term commitment and depth that they once had, being replaced by mutually unconnected interactions ('transactions').

Sennett argues that it is within the finance, technology, pharmaceuticals and media sectors that this new culture of capitalism is most firmly established. And many studies of finance in the City of London have come to similar 
conclusions. Many argue that deregulation in the 1980s had social consequences which made social relations less personal and more 'transactional' in the new City. Amongst the more significant of these studies has been the work of David Kynaston. In the last of his four volumes on the City of London, Kynaston (2001) discusses the end of the 'club' and the development of a 'modern', internationalized City, characterized by a new seriousness and competitive money making as the US investment banks swept away the old style merchant banks, and an 'aggressive' 'trader-based culture' replaced the 'age of deference' (Kynaston, 2001: 756).

This view of a past involving close personal 'club-like' relations was echoed by Anthony Sampson when he suggested that in the past 'the City was governed by "gentlemanly capitalism", with unspoken rules about what "wasn't done" and by personal relations ... and the assumption of trust was summed up in the motto of the Stock Exchange: "My Word Is My Bond", (Sampson, 2004: 241; see also Sampson, 1965). According to Sampson, 'behind all the conventions lay the assumption of a club based on common values and integrity' (2004: 241). Much earlier, Victor Sandelson noted that, 'on this assumption of trust reposes the whole structure of the City' (Sandelson, 1959: 133). These 'traditional' attitudes and relations are often represented as having been a barrier to coping with the transformed conditions brought in by the 'new capitalism'. For example, Philip Augar's (2000, 2005) insider account of the transformation of investment banking blames the demise of British-owned firms on the failings of the class-bound, amateurish British merchant banks as much as the quite different culture of what were regarded as the US interlopers'. Many other authors present normative accounts where the changes in the City were part of a move towards a more 'short-term culture' in a financial sector interested in fast money-making more than the 'pyschic reward of trying to build something' (Kynaston, 2001: 755; see also Peston, 2008: 183-8 and Hutton, 1995). There is a strong moral story that accompanies these accounts: commentators are split between whether the changes are leading to greater moral decay and social fragmentation on the one hand, or greater personal freedom and opportunity on the other. In making sense of changes in the City that were part of the development of PE, it is important to understand what the practitioners and builders of this new capitalism think is going on, given that what is being discussed is an apparently new attitude or (a)moral sensibility that informs the development of these new financial sectors.

Some researchers have used Sennett's relation versus transaction opposition to understand change in the City, assuming that the story broadly reflects reality, and that the relational past is apparently disappearing; but many also challenge the opposition by examining the content and operation of these past relations. The idealized story was that a London gentleman's club was based on shared social background and elite public school training, and this established high levels of mutual trust through exclusion and surveillance: 'decent behaviour' was (ideally) guaranteed by strongly socially monitored and controlled codes of conduct, and a system of exclusion that ensured everyone was 
broadly similar in background and attitudes (Aaronovitch, 1961). These ideals set little store by the achievement of professional qualifications; and, of course, such clubs axiomatically excluded women and ethnic minorities. The club notion also implied that informal sanction within the insider group was a substitute for any formal system of regulation (Courtney and Thompson, 1996: 164). But, as Sampson and Kynaston both point out, the old City was also riddled with insider trading and functioned as a cartel. This implies that perhaps the ideals of 'trust' and 'integrity' were as much convenient rhetoric for insiders as they were a description of actual behaviour. As Paul Thompson reminds us, 'gentlemanly capitalism' has often been used as a descriptive label rather than as the basis for analysing how social background 'influenced the changing work culture' of those who worked in the City at the end of the twentieth century (1997a: 286).

That kind of appreciation of the complex relation between stereotypical ideals and the social contexts to which they are linked is useful. As Herzfeld (1997) notes, stereotypes are not simply untrue, though they usually exaggerate and simplify what they describe: where social relations and moral values are concerned, stereotypes can become self-fulfilling prophecies, acting to both create and maintain the values and relations expressed, and to render invisible alternative perspectives. This points to the value of paying close attention to such stereotypical ideals in analysing the development and maintenance of new social contexts such as the private equity sector.

In this context, the City Lives interviews provide a wealth of information about family backgrounds, careers, attitudes and the experience of working up through City organizations (Thompson, 1997a, 1997b; Courtney and Thompson, 1996). They cover the period before deregulation when the financial sector had been heavily compartmentalized so that merchant bankers, insurance and commodity traders, stock brokers and jobbers all lived, structurally at least, in separate small worlds with their own particular interpretations of rules and hierarchies. From this perspective, it is interesting to turn to the more recent research of Aeron Davis (2007), whose findings imply that new sectors of this type have been created as old ones have waned. Davis presents the fund managers, journalists and analysts involved in the valuation of equities in the London Stock Exchange (LSE) as part of a small, reasonably stable part of the financial sector. Unlike some large markets (eg global currency markets) where players will not know each other, the equities market around the LSE brings together a relatively small number of players, who are often rivals, operating on a network basis.

The world of investment banking is on a much larger scale, at least since the rise of proprietary trading in the later 1990s. This activity required a different kind of workforce than that involved in old fashioned merger and acquisitions and underwriting, where personal relations with corporate clients were important. But Sarah Hall's (2009) work suggests that this new part of the sector is networked, albeit in different ways from the old types of relations. Hall characterizes the change as one from 'power as capacity', where social and educa- 
tional background is important (and in correspondence with Thompson, 1997a), to 'power as mobilization' (2009: 180-2), where senior figures have the social capital to organize teams to deliver products. If the right schools and clubs no longer matter, Hall implies that nevertheless, successful transactions depend upon personal relations (Hall, 2009: 175).

These studies suggest two things. First, that many different parts of the financial sector exist, and not all of them share the same values and norms, and not all have been changing in the same ways. This means any global theory of shifts in trust need to be studied in detail within each context. And second, the relationship between stereotypical assertions and ideals, and practices on the ground are complicated and need careful study: the meaning and experience of trust cannot be taken for granted.

So are there some common characteristics to understandings of 'trust' as an abstract concept, which can help us to explore understandings of trust in ways that take us beyond a relational versus transactional dichotomy? Here, Carol Heimer's work is helpful. Her argument that 'uncertainty and vulnerability are the core elements of trust relations' (2001: 43) and that, in specific contexts, strategies are employed to reduce (though not eliminate) these elements, provides an excellent starting point. In traditional societies (by which Heimer means interactions are mostly based on personal relations), the emphasis tends to be more on reducing uncertainty, such as through controlling the behaviour of others; while in modern societies (by which Heimer means that the state, the legal system and other institutions take the place of personal relations in many economic, and some social, contexts) vulnerability tends to be the focus, through use of technologies such as insurance. However, she suggests that the specific strategies chosen depend on 'the social structure of a society or group, which in turn affects the resources available to people and the cost of using one strategy rather than another' (Heimer, 2001: 59). Moreover, Heimer argues that the nature of the trust relation depends on factors such as the possibilities and threats of recourse; the numbers of people involved and their disposition to be accepting or suspicious; the density of networks and the ways information about trustworthiness can be transmitted; and what is at stake in terms of the extent to which the individual is exposed to interactions with the group (Heimer, 2001: 60-61). Heimer's approach is useful for our study because it highlights the nature of the social relations within a group and it considers diverse contexts in which the practices and understanding of trust varies. Paradoxically, while there is public distrust of private equity, this does not mean that there is no personal trust within the organization: Coleman (1990) argues that reciprocal dependence and the opportunity to build relationships and knowledge over time is more likely to create incentives to be trustworthy and to trust, and this seems to be borne out for senior PE partners. And, as others have highlighted, the positive of trusting implies a negative of dependency, vulnerability and the risk of betrayal (Barbalet, 2009: 369; see also Gambetta, 1988 and Luhman, 1979), an element also highlighted by our interviewees. 
Beyond the abstract concept of trust, the act or practice of trusting has attracted varied approaches. Berezin (2009) sets up the distinction between trust as cognition and trust as emotion in the introduction to a special issue of Theory and Society on emotion and the economy (see also Pixley, 2004). However, Berezin argues that trust is rational and should not be treated as emotional: she draws on Coleman's (1990) argument that 'trust is "a bet on the future" that we place with respect to knowledge we have about past actions' (2009: 340). The emotional part, Berezin suggests, is the confidence that accompanies this cognitive 'bet' (Coleman, 1990: 343). In more economic terms, Hardin (2001) presents a rationalist argument, suggesting that the decision about whether and when to trust is about self-interest, not disposition, and that people use various actions to help solve problems of trust, such as monitoring or contracts. This practice-based and calculative approach is distinct from generalized notions of trust and can be formalized into accounts that focus on the dynamic between principal and agent, or game theory problems (eg Gibbons, 2001).

This wealth of literature provides many useful tools for thinking about trust. The problem is, as Shapiro (1987) points out, trust can take many different forms, and if the focus is to analyse whether trust exists and what conditions generate it, then the problem of what constitutes 'trust' in a given context, and how that understanding affects the context in which it exists, is side-stepped. So while research on trust has demonstrated that the nature of trust relations and the ways in which trustworthiness is assessed and acted upon strongly depend on context, there is still work to be done on the relation between trust as a concept and these diverse contexts. So the next area to consider is studies of particular social contexts and the way in which trust becomes involved in them.

There are, of course, many studies of trust as expressed in a range of organizational and societal contexts (see for example Cook, 2001 and Kramer and Tyler, 1995). The one we choose to highlight here is Gambetta's historical study of the Sicilian Mafia (Gambetta, 1993). This study provides interesting material for comparison with our PE case, not only in terms of what constitutes trust, but also the strong emphasis early Sicilian Mafiosi placed on particular stereotypical ideals of trustworthiness, which centrally included harsh punishment for breaches of trust, as a key defining characteristic of the Mafia world.

Gambetta (1993) argues that during the transition from feudalism to capitalism in Sicily, some people spotted a business opportunity. That business was protection of private property: in conditions of a weak state that could not guarantee contracts, the Mafioso basically guaranteed business deals. He did this not only by threatening violence towards those who did not abide by their agreements, but also by knowing a great deal of local information: he established networks of kin and friends who could be relied upon to provide accurate information about what was going on, and developed a reputation for being a tough, violent but most importantly honourable man, who could be 
trusted at all times to stand by his word. Importantly, Gambetta argues that these men, who were, in his view, minor representatives of the emerging bourgeoisie, departed from 'traditional' Sicilian social relations in one important respect: they were not linked to networks of power through traditional kinship links or patronage, but instead through personal, and mostly entirely financial, relations with those in power. In other words, Mafiosi had autonomy; and although they strongly promoted the idea of adherence to moral principles such as strong family values and honourable behaviour at all times, they rejected being dependent upon the earlier aristocratic and patronage model of power. By emphasizing the Sicilian time-honoured values of integrity and trust (backed up by the underlying threat of violence), while also breaking free of ties to traditional sources of power, Gambetta argues these men effectively created the social and practical conditions for a new business, which eventually came to be known as 'Mafia', in no small part because of media attention, greatly enhanced in later years by novels and Hollywood (Parker, 2010).

The interesting thing about Gambetta's study is that, while dense social relations and an appeal to Sicilian ideals of honour were crucial elements that 'Mafiosi' used to develop their role as people who guaranteed deals, there was an equally strongly emphasis on the threat of some highly unpleasant consequence if both sides did not keep to their side of the bargain. Trust in the word of the Mafioso, based on their family's reputation, might have been an important social ideal to appeal to for a man to build up his Mafia 'business', but the 'guarantee' of the Mafioso's ability to secure the deal was provided by his ultimate threat of violence. Obviously, private equity in 2000s London is an entirely different social context from late nineteenth-century Sicily. The two key points of comparison for us are: first, the Mafiosi's emphasis on absolute trust combined with dire consequences for breaches of trust as the key defining feature of the Mafia business; and second, the conditions of insecurity and uncertainty in which the Mafia business developed. That second point leads into the next section, which explains key features of the private equity business in the UK, and something about the background of the senior partners with whom we talked.

\section{The activity of private equity}

Private equity is a relatively new part of the finance sector and did not exist before the mid-1980s. It was rapidly upscaled and reinvented in the 2000s under conjunctural conditions that were favourable to making money from leveraged buy outs, where most of the cost of buying an existing company would be covered by borrowing at fixed rates of interest. This section outlines the distinctive characteristics of private equity as an activity that operates as a small and fairly close-knit part of the financial sector. This was also an activity in which making money was the result of non-standardized processes with 
highly uncertain outcomes, and in which the seniors who were in post in the 1990 s were lucky in the conjunctures of the 2000s, because all had an opportunity to accumulate significant wealth. Together, these elements helped to establish the context in which the activity of private equity developed, the emphasis private equity practitioners placed on trust and the kinds of individuals who were attracted by, and succeeded in, the business.

This account is based on publicly available information on the PE industry and semi-structured interviews of an hour and a half or more with five of the founding fathers of private equity in the UK, which were recorded and transcribed. The interviewees agreed they could be quoted if we kept their identities anonymous. All five had been in the PE business for twenty years or more and all had been exceptionally successful. As successful founders of private equity in the UK, they were of course much more likely to have a positive view than those who were less successful and who, for one reason or another (including dismissal), left the private equity sector. Our focus on these men was deliberate: we wanted the views of those who shaped the business from the top.

Survival in PE had not been achieved without trauma, as one interviewee had recovered from a breakdown and another had acrimoniously fallen out with at least one of his previous employers. Two of the five were co-founders or builders of very large British private equity firms that had scaled up their fund and deal size in the 2000s; another two had stayed with mid-capitalization deals and smaller firms; the fifth was fairly recently retired and no longer raised or managed funds as the others did, but he remained socially well networked. Four of the five had been involved, either as individuals, or via holding office in trade associations, in public affairs and in representing PE to politicians, regulators and the public; two of the five could be called celebrities in the business world, with some profile and name recognition in the business press, while others had chosen to remain below the media's radar.

On, then, to a brief description of private equity as a practice. In simple terms, the business of private equity involves raising a fund from private and institutional investors which is then re-invested by buying several operating (portfolio) companies with a view to selling them on profitably within five to seven years, after which the fund is closed and investors receive their returns (Froud and Williams, 2007). While these portfolio companies are in PE ownership they will be closely managed and possibly refinanced, so as to extract cash (via special dividends) or to improve saleability by cost cutting, growth or consolidation, depending on the firm or sector. Unlike venture capital, private equity funds specialize in buying established businesses, not funding start-ups, and much of their profit over the holding period depends on the trend of stock market prices which set the benchmark for what companies are worth. If the market goes up strongly, careless PE buyers will still make a profit. In the period from 2002 to 2007 when debt was relatively cheap and easily obtained, private equity funds used leverage to increase their purchasing power. When 80 per cent of the purchase price was covered by money borrowed at low rates 
of interest, the PE fund's equity investment gains were levered up. With asset markets rising and cheap debt available, the average size of a PE transaction soared from around $£ 4$ million per deal to over $£ 15$ million over a five-year period (IFSL, 2008). Private equity became much more publicly visible as PE funds bought up household names such as the AA, Bird's Eye, Debenham's and Boots in the UK. Hostile critics represented PE partners as financial engineers who behaved irresponsibly and rewarded themselves handsomely (see Folkman et al., 2009 for analysis of the debate).

By the time we conducted our interviews in 2008, British PE had been reinvented in the previous decade as some (but not all) PE firms, funds, deals and rewards had become much bigger. All interviewees remarked on the rapid changes and some indicated a degree of nostalgia for an earlier world of quick, informal decision making and 'hands-on' management of portfolio companies. Arthur, who had not up-scaled his activity as much as others, compared a large PE firm with his own mid-sized one:

Everything about it is different. At the very large end they became a conglomerate and financial managers with very little engagement with the companies because they were typically hiring superman to run it, so you let him get on with it. At our end it's still very messy and fun, but . . they make more money than we do.

Up-scaling did not, however, change three key elements of private equity: first, it requires commitment by partners over the long term; second, deals are infrequent, always different and the contribution of individuals can be easily identified; and third, making money on deals depends partly on judgement but also on timing, luck and a favourable trend of asset prices. It is worth looking at each in more detail.

First, partners are effectively locked in for the life of the fund because their main financial rewards, the share of the profit on selling investments (known as 'carried interest' and usually around 20 per cent of fund profits), will only be realized at the end of the fund's typical ten-year life. In the meantime, the portfolio companies must be acquired without overpaying, managed for profit during a period of PE ownership, and sold on at the right time to maximize profit. One of the interviewees, Arthur, drew a contrast with investment banking, 'where treading on people as they go past is considered fine. You only need to make three or four years of bonuses, then you're off in the big wide world to do something else.' In private equity, the time horizon can be a decade long and all interviewees emphasized that relationships between the principals within a firm become important because of this.

Second, the contribution made by individual partners to profits is obvious because each partner typically champions particular deals, so they are easily identified with good or bad results. At the same time, interviewees suggested that nobody can tell in advance whether a new partner has 'what it takes'; nor is it easy to spot when an established partner has 'lost the knack'. While all 
interviewees stated that no partner can avoid losses because of the inherent uncertainty and all recognized that most of the fund profits would come from a minority of the deals, they also agreed that a string of bad deals could end an individual's career. This happened in the case of one of Arthur's previously successful partners, whose recent deals had cost the partnership $£ 50$ million.

Unsurprisingly, what makes a good dealmaker was of considerable interest to our interviewees. PE is unlike other kinds of City trading because the number of transactions is small and each company to be bought or sold is different, so standard valuation formulae can act as guides, but cannot be the basis for deciding whether to trade. For similar reasons, academic qualifications were not a guarantee of success, though most interviewees emphasized they only recruited the highest of academic high fliers, so that was a necessary, but not sufficient, criterion. Chris emphasized that the need for rounded 'good judgment' applied to appraising economic context, business plans and personalities. This requires synthetic rather than analytic ability: George contrasted 'good analysts', who often focus on more and more detail and information, with 'conceptualizers' who 'will have a story. What's the big picture, what are the three key things....' The ability to act and intervene is also important because the successful partner is 'personable' and 'persuasive' on the deal and the follow-through. Thomas talks of having the 'good sense' to know what will work and a 'good gut' about acting decisively on tricky operating issues, such as whether to advise or dismiss portfolio companies' managers. In their characterization of the dealmaker as someone with diverse attributes, the interviewees emphasized the distinctiveness, in their view, of private equity in comparison with other financial activities.

Third, while internal skill and judgement are important, successful dealing depends on unpredictable and variable external circumstances in each new conjuncture or phase, so that funds and partners sometimes find it easy and sometimes difficult to make money. As already outlined, the conditions of 2002-2007 favoured private equity dealing because purchasing power could be leveraged up with cheap debt, existing investments could be profitably refinanced and companies could be sold into rising asset markets. Furthermore, the tax on carried interest, that constituted the profit on the fund allocated to the PE partners, was changed by the 1997 Labour Government; as PE assets were held for a long period, these could be treated as capital gains and not income, leading to a much smaller tax being paid. ${ }^{4}$

Several interviewees admitted that the successful partner and fund needed luck as well as skill; one noted that in favourable conditions, it was possible to make money despite poor judgement. For example, Arthur notes that: 'hard work and intelligence... [are] important but ... [that] doesn't get you anywhere if the tide's going the wrong way. The tide has been mostly moving the right way over my career'. After 2007, the drying up of credit and the collapse in stock market values made it hard to both buy and sell, and signalled the start of a new, less profitable phase. 
In sum, PE appears to be a particularly uncertain business. All PE firms have investment committees and other structures to vet investment proposals. But formal criteria are impossible to set because the PE partnership does not have a core product or process which sustains a predictable flow of turnover and cash so that investment return and pay back can be projected. So who were these people who had survived, and indeed thrived, in a world where great fortunes could be made but where there were few rules or guarantees?

The PE founding fathers in the UK were, unsurprisingly, overwhelmingly male, white and middle class. Only one interviewee came from a working-class background, while another who came from an industrial town pointed out that his (lower middle class) father had a car when other parents did not. Chris noted that most of his peers are, 'middle class, middle income, university type background, 45, white, male, but now worth quite a lot more money. They all trained as accountants, trained as lawyers, did a bit of work in a firm, fell into private equity by mistake.'

Those who 'fell into' PE 'accidentally' were part of the first generation of financiers in the UK where elite educational achievement was an entrance requirement. The City Lives project described the old City before the 1980s where, as Thompson (1997a) notes, it was important to go to the right school, but university education or professional qualification was unusual. In contrast, all five PE interviewees had university degrees and three had Oxbridge degrees. These same three also had Ivy League MBAs, while the other two had qualified as chartered accountants.

These PE trail blazers in the UK were also united by their rather proud rejection of standard corporate careers. After education and training, most joined either consultancies or blue chip firms but all recalled how they were dissatisfied with the experience of working for such large organizations, despite early successes on standard career paths. After university, Thomas worked successfully for one of the most prestigious US consultancy firms and turned down the first offer to work in a fledging UK private equity firm before accepting a renewed offer in the early 1980s: 'it seemed a risky, but quite exciting, thing to do. But compared to sitting in some office somewhere off a long corridor in corporate Britain, it seemed more fun.' George commented that he disliked the 'culture of large companies' because they recruited 'very bright people but didn't give them interesting things to do'. In short, these were men who wanted to run their own businesses, not work for somebody else; subsequently, of course, several built large firms not so dissimilar from the ones they had rejected in earlier years.

All interviewees described working in private equity as being 'fun', whether it involved building up a large firm with fellow partners or running smaller operations with fewer principals and with more hands-on involvement. David recalled how he turned down a job with a leading investment bank in the US for one in British PE on a quarter of the salary because he thought it would be 'a fantastic learning experience'; he also added that he knew at the time he would get a share of the carried interest and the opportunity to be a partner at 
a much younger age than would be possible in investment banking. Arthur told how finding out about new businesses is part of the attraction, while Chris more effusively argued that private equity had been, 'such enormous fun'; the combination of intellectual challenge, the range of businesses and the people meant that for him, 'it's the best job I've had in my life'. In some cases, the move into private equity came about via personal contacts with someone else who was already in that field. For example, David explained how he had been wishing to move into private equity and a chance encounter made this possible:

My father was in a train with X, who at the time was the chief executive of [a major investment bank], and X said ... we are about to start a venture capital business ... and if David was interested he could send his résumé to a guy called Y, who was also actually a [top 5\% graduate from the same US business school]. So we kind of had an introduction from X, which was helpful, and there was an identification between the two of us because we'd been to the same institution.... Y introduced me to someone who knew nothing about [the business school] at all, who was [interviewee Arthur], who was the guy they had recruited from a venture capital business to come and run the business.

Most interviewees expressed a great sense of achievement about how they had been part of the development of PE in the UK. They presented themselves as mavericks with non-standard career paths, and all said they were intensely competitive. Chris noted that 'many of the people in our industry are driven, enormously competitive, alpha type people', after describing his own beginnings in the business in terms of high competitiveness. Thomas likewise expressed this emphasis on competitiveness, stating explicitly that he wanted to succeed in everything he does, including private equity, sport and, more recently, philanthropy. He mixed this emphasis on competition with small doses of self-deprecation: 'I can't play a game without wanting to win it, definitely. In stark contrast to my son, who plays a game and is indifferent to who wins it. Maybe he has a rounder personality than me.' David expressed something similar when he explained that there is competition within firms as well as between them, with partners who quietly 'keep score' in terms of how much they have contributed. Interestingly, one of the firm builders, Thomas, mentioned that personally he preferred the world of venture capital to that of private equity; but then he explained that he could not have stuck in venture capital because he wanted his firm to go global and be amongst the handful of largest global companies, and that required being part of the PE world of large funds and large transactions.

At the heart of these interviewees' definition of success was the assertion that making money is the key measure of outcomes. The fee structure of private equity, which combines a management fee (around 1.5 to 2 per cent per annum) on the fund and a 20 per cent share of profits at the close of the fund, 
has always been designed so that successful deal making and execution would make the seniors in the PE firm extremely wealthy. In the 1990s, the most successful players personally made tens of millions of pounds, and in the 2000s, seniors who up-scaled to larger funds and deals could make hundreds of millions. Anyone who aspired to such wealth had to first raise a fund and manage multiple re-financing, while buying and selling companies over more than five years, in conditions where the outcome was unpredictable because it was both dependent upon stock market conditions and, crucially, on the reliability of a small number of people. In short, these interviewees described the PE sector as depending upon relatively long-term relations between a small group of people who had to trust one another sufficiently to place extremely large quantities of money, and the chances of success or failure, in one another's hands. So the next section explores how the interviewees described the character and significance of trust between the partners.

\section{The principles of brittle trust}

In describing their own lives, interviewees placed personal integrity and mutual trustworthiness at the centre of their accounts. And this was not simply expressed as an abstract value, but a key to success in the PE world: mutual dependence in order to achieve collective success required, in their view, extremely high and consistent standards of reliability.

In this section we explore our interviewees' accounts of the making and the breaking of this deep personal trust, including the distinctions they drew between UK PE and other parts of the finance sector, as well as the way that the investment committee operated. In doing so, we also contrast the kind of deep mutual trust described in the relations between partners with the relations with more junior colleagues and those hired to manage the portfolio companies bought by the fund; in these cases the form of trust is described quite differently, yet there is the same impression of harshness when things do not work out.

When asked, all interviewees easily described the ideals of their own conduct and those of others in relatively explicit terms: all asserted there was a set of principles that everyone in UK private equity understood and for the most part, abided by. Interestingly, their descriptions were similar to the stereotyped old City rules discussed earlier, and included the importance of 'personal integrity', which specifically meant: keeping your word, reliability, honesty, responsibility, fairness, hard work and equal commitment to family and work. Thus, this new world of money-making was constructed as one that retained and adapted 'traditional' values. Moreover, these values were of use to senior partners in dealing with the uncertainty and vulnerability of the PE business. The characteristics of the trade discussed earlier generated a strongly perceived need to ensure that everyone understood the principles and values that must be followed in conducting business; and, equally important, that 
these principles would be rigorously monitored and policed: behaving inappropriately would result in instant, and harsh, responses.

Interestingly, interviewees described these principles and the strong monitoring of them as being instrumental (ie for the practical and material benefit of the group, including themselves) rather than as adhering to any general moral good. In this sense interviewees echoed what Hardin refers to as 'encapsulated self-interest' (2001: 19): representing themselves as acting in a calculated and rational way to maximize the chances of success. All interviewees emphasized that these values worked in making a success of the business of private equity.

Logically, this instrumental approach implies that such values would be abandoned if better ones came along. However, that was not what interviewees reported: the defence of these principles was strong, even when faced with the possibility that other approaches might work just as well - and in particular, when faced with what was understood to be the 'American Way'. In fact, several interviewees received training in the US, and they explicitly described this training as useful to them subsequently in the UK; but the underlying principles of conduct in the UK were, it seems, somehow different from those more common within the US private equity sector. This points to our interviewees' understanding that they were describing how the principles they followed helped to actually shape the particularities of the practice of $\mathrm{PE}$ in the UK; it was not simply a matter of pragmatism, but guidelines for the building of a PE 'world' that took on distinctive characteristics; this was a world with which they were comfortable and that they actively helped to create.

Here, stereotypical contrasts drawn between the US and the UK by interviewees is instructive. The American-owned private equity firms with London offices were, by the 2000s, competing on the same deals with the British firms right across Europe. Thomas said, for example:

I think we were a bit more gentlemanly in the bidding process. I mean, we'd never say we'd bid more and then drop the price at the last minute. That sort of wasn't British - though some of our British competitors didn't mind doing that.... Whereas the Americans were much more aggressive on that score.

At the same time, Thomas, who was one of those trained in the USA, also suggested that he had learned to get into the habit of being philanthropic through his experiences in the USA. The point is that there was a difference, whether or not it was negative or positive: even the suggestion that the Americans were more 'aggressive' than the British was not necessarily an entirely negative remark, at least from the perspective of effective business practice; but it was not the same as PE practitioners' conduct in Britain.

Stereotypical contrasts were also drawn with other parts of the financial sector in the UK. For example, Arthur echoed the City historians and Sennett on epochal change: 
the social fabric of the City nowadays is very different. Personal relationships are less significant by a long way. ... The old City - fit and proper, honesty, integrity, my word is my bond - there actually was quite a lot of that. Now it's grab the bonus, transactional, not a relationship.

Arthur then added the Pharisaic qualification that PE was 'different' and that, in his view, standards of integrity were lower in investment banking. In fact, most suggested, without prompting, that investment banking had 'lost its moral bearings'. Arthur explained that in private equity he could rely on close colleagues, but, 'it's different in an investment bank, it's short-term gain. ... People are contemplating longer careers here [in private equity], so that means more of a relationship, less the transactional.'

The image of PE that emerged from these contrasts was the financial sector with long-term relations based on reliability and integrity. Thomas emphasized a strong trust between the fellow founding partners of his firm; David spoke about 'a sense of reliance and trust' that is 'particularly strong in the partnership group'. In the larger firms, the senior group would normally be fellow members of the investment committee: this committee approves proposals to buy or sell companies and must then make a judgement about whether to do the deal, how much to spend (or accept) and about timing. To make such decisions, investment committee members typically rely upon information provided by the one member who is sponsoring the deal.

All interviewees gave some account of the norms under which investment committees operated in their firms, stressing the importance of being able to rely upon the assurances of fellow members. Some also mentioned that what they saw as the 'inherently competitive' nature of PE meant it was nevertheless sometimes hard to build trust with particular individuals. All interviewees also discussed a need to understand their fellow investment committee members' personalities and approach towards the job so that they could interpret appropriately a sponsor's recommendations. Thus, while this personal mutual trust was to a great extent apparently based on cognition (ie that being reliable and honest contributed to an effective decision-making process), there was also a degree of confidence based on assessments of personality that were built up over time. Chris further asserted it was important to reach unanimity on key decisions, which would prevent recrimination at a later point, and be a strong test of the merits of a proposal. In this sense, the accounts of our interviewees reflect Barbalet's (2009) argument that trust co-exists with confidence.

Most of the interviewees thought it important to devise methods of achieving consensus about going for a deal that would avoid creating resentment in a colleague whose idea has been rejected, and would avoid wasting too much team time on a deal that was never going to be accepted. This was one way of dealing with what they recognized as the individual vulnerability created through the collective decision process; this also recognized the social as well as the business importance of a harmonious, effective investment committee 
and, in turn, helped to strengthen the institution and their understanding of it.

Collectively, these accounts painted an image of an exciting, tough, risky business that attracted highly intelligent and competitive men (sic) who had to rely on one another to collectively succeed. The image obviously includes an inherent ambivalence: simultaneously strong self-interest and a requirement of long-term collective commitment. This is not the image of the pre-1980s, pre-deregulation 'gentleman's City club', though many of the idealized values of that period - particularly the ones involving personal integrity - have been explicitly adapted to suit the new context. What was explicitly abandoned from that earlier period was the idea of ascribed status and, with it, the idea of unquestioning loyalty: those values were replaced in the descriptions of our interviewees by principles of (repeatedly) demonstrated achievement and both instant and permanent exclusion for any breach of personal integrity. This was the key clear distinction drawn between 'then' and 'now': the UK's PE sector would not tolerate underperformance in the name of loyalty, and could not afford to give anyone a second chance if they broke the rules of integrity.

This deliberately and explicitly harsher environment emerged clearly in interviewees' descriptions of private equity as a business; indeed, it was emphasized as much as the demand for absolute trust. George, for example, commented that,

You are in this together. You cannot second-guess your colleagues. Once you have any doubts about whether they are telling you the truth or being frank, the game is over. If they say I've been to see $\mathrm{x}$, this man's reliable, this man's not... If you doubt that they have checked that and they are not reliable, then the game's over, in my view.

Any form of deceit was represented as an extremely grave matter that would normally end a partner's relation with the organization. David commented: 'There is an understanding and a trust within the group.... Alan Sugar recruiting someone who had lied on their résumé. Well, that's unthinkable, it just wouldn't happen. It would be the end'. David was equally adamant that an isolated lapse by a generally trustworthy colleague could not be shrugged off: 'I think there is such a strong understanding, that that could not really be forgiven'. To be clear on this point, David drew a distinction here between misleading colleagues and making a mistake:

You can say, I think this is a good business, and actually it turns out to be a crap business. Well that's fine. Everyone knows that happens. We all make those mistakes. But to say, we have checked x, y and z, and you hadn't. That would be completely unthinkable.

The principle being described here was what we refer to as brittle trust: strong and based on long-term commitment and mutual knowledge (as well as group 
monitoring), yet easily broken. Importantly, both parts of this principle were equally emphasized. It was not that regular dismissal of partners was an unfortunate necessity in this high-risk business: on the contrary, such dismissals were represented as a positively healthy part of the business. Arthur stated that, 'If we don't lose a partner every two years, I would suggest that would be an unhealthy environment.' David suggested that, 'We fire partners. Lots of partners. Not one every three years, more than that.' The tendency to shed staff, even at the highest levels, was thus depicted as an inherent and key characteristic of the PE business: it is what the context demanded. Of course, the people representing it that way were also the ones who built the business in that image.

The abandonment of the principle of ascribed status was thus accompanied by abandonment of any expectation of unbreakable bonds in relations between people, while retaining principles of mutual integrity and commitment. Interviewees most often described this as a rational or pragmatic approach: the principles were followed because the context required them though recall the contrast with the 'American Way': other principles could also have 'worked' in purely pragmatic terms. So this was also a description of how these men chose to build the social context of the private equity world in the $\mathrm{UK}$; it was not simply the description of a rational calculation.

This concept of brittle trust, depicted as contingent and non-negotiable, referred particularly to the relations between the small group of fellow seniors, rather than its daily operations at a lower level. For example, when dealing with more junior staff in the PE firm, interviewees described more of a conventional principal-agent relationship. Chris described how trust in juniors was built on performance alone; an echo of the underlying principle of harsh consequences for failure to perform at the highest level was present, but there was no hint of the deep level of mutual trust described for senior members of the firm.

Interviewees also described different kinds of relations with other PE firms and with portfolio company managers. A more familiar transactional approach was described in discussing relations between PE firms; firms buy portfolio companies from each other, and also compete for purchasing new companies. Here, Chris talked about the need for reciprocity, or 'fair dealing', in relations with other PE firms, where reputation mattered. George emphasized the pragmatic argument that, within the PE business, it was sensible to avoid giving offence to individuals with whom you will most likely have repeated interactions in the future, and with whom you may even end up working. Recall the ideal of regularly dismissing partners: such people may need to find work elsewhere.

Professional managers hired to run the portfolio companies which private equity funds buy were different again. These were represented as people hired to do a particular job: the job, not the person, mattered most here. Those perceived as doing a good job would be hired regularly but there was no effort to establish trust or commitment with these people, and no hesitation in 
dismissing them 'as needed'. Thomas remarked that managers would never be trained; they would simply be replaced: 'in big companies . . . if they don't know [how to do the job well] by now, they're not going to learn, so you need to get another one'. Chris concurred, adding that while it was often necessary to woo managers and offer them attractive financial rewards before they were hired, 'afterwards the relationship changes . . . because then these guys have to deliver'. For Arthur, if someone does not deliver, 'the preferred routine is to take them out and replace them with somebody better'. David added that it is 'only responsible to replace under-performers, in the interests of the employees and the investors'. Thomas added that in some cases a manager might be rather unfairly (but expediently) branded as 'under-performing' because 'it is probably easier to say that the manager can't do his job than say, well actually, my whole research in this company is flawed, and the whole concept is daft'. In such circumstances a portfolio manager takes the blame in order that the investment committee can continue to believe that their original decision was correct.

Here again, the echo of 'necessary ruthlessness' that was used to describe all other levels of PE dealing was the one common factor in discussing managers of portfolio companies. This could be called an 'immutable mobile' in Latour's terms: a principle that is maintained across different contexts and times even while all else changes (Latour, 1987: 227). As such, it appears to be a key defining factor in how $\mathrm{PE}$ as a practice was imagined by our interviewees. Some relationships were described as being more or less managed directly through contracts and rewards: thus an 'up-or-out' system for internal promotion, or hiring and firing portfolio company managers, were largely described in the narrow, apparently asocial, terms of performance and consequences. In other relations, a demand for absolute and deep trust was necessary. In all cases, any breach, either in performance or integrity, would be instantly and harshly dealt with. That was the common thread, the main defining principle, of the business.

\section{Conclusion: the logic of brittle trust}

Private equity specialists in the UK, along with many others, were prone to occasional stereotypical generalizations. Many described an era of less moral, more fragmented, more aggressive, yet also less hierarchical practices than existed in the old days of noblesse oblige, within the gentlemanly City. Ironically, given that the media has identified private equity as being the poster boy of the 'immoral' new financial sector, interviewees simultaneously insisted that some of those old values, the ones involving absolute trust and integrity, had been retained in their sector, even if they had been lost in others (eg in investment banking). Yet this trust and integrity was not described as being based on ascribed status - on being born into the right family, being socially the same as your colleagues, having been to the 'right' schools and universities, 
belonging to the right London clubs (even if many did actually meet these criteria). That old reliance on ascription was replaced by ideals of repeatedly demonstrable intellectual and personal skill and repeatedly proven trustworthiness and integrity: every act was monitored, and any fall in standards instantly and permanently punished. That was the key element of change in social relations that the founders of private equity insisted upon; and it is what they built into their business as an uncompromising guiding principle. People in private equity, they argued, had to work with each other over long periods of time, which required much more care over how people behaved towards each other than was expressed within, for example, investment banking. In this sense the appreciation of the environment in which PE operates governed the kinds of trust relations that senior partners considered were necessary (which is not to say that they could not have chosen different ones that would have been equally effective). As they saw it, trust was mutual, not hierarchical between partners; the outcome was uncertain and the stakes were high in the sense that gains or losses could be very large. The long-term life of the fund provided both the opportunity and the motive for building deep, albeit always contingent, personal trust. As partners understood each other, confidence could be built in their own judgement to trust. However, there were still group strategies, such as the need for unanimity in the investment committee that served to reduce vulnerability. In turn, our interviewees seemed comfortable with this account: the notion of brittle trust, deep yet easily broken, was a natural reverse side of a business where large personal fortunes could be made.

Our interviewees justified the new harshness by suggesting that they were both mavericks who up-ended an old world in the City, and that what they chose to do was the most rational solution to the business conditions that confronted them. They represented themselves as creating an opportunity that presented itself in the 1980s: over two decades, they forged a new part of the financial sector that was incredibly financially rewarding and intellectually stimulating, but also uncertain and highly risky. That situation led people to rely upon familiar principles and values, but in a way that suited the changed circumstances. This effectively describes the deliberate creation of a new social context: not one that entirely abandoned past principles, but rather appeared to retain them while explicitly jettisoning the key conditions that had usually been credited with generating those principles: ascribed privilege and irrevocable loyalty.

This returns the story back to Gambetta's account of the Sicilian Mafia: according to Gambetta, the first Mafiosi appealed to very similar 'refashioning' of the traditional Sicilian ideals of honour and integrity, and also explicitly jettisoned their links of dependency with established and traditional power. Although the Mafia is obviously in a very different kind of business from PE, the similarities in these stereotypical ideals of absolute integrity combined with uncompromising punishment for a breach, are striking. The social context had some parallels as well: both the Mafia and private equity developed in 
relatively unregulated contexts and involved high risk and potentially very high gain activities with no safety nets. In such situations, it makes sense to make extremely high demands of social relations: a simultaneous insistence on absolute integrity combined with harsh punishment for breaking the rules (or what we would call brittle trust). People in the Mafia who broke the rules of honour, honesty, integrity (and silence) also paid a high price. As Parker, who studied the way both fiction and media have collectively made the Mafia into a self-fulfilling prophecy, put it: 'Mafia members who forget omertà and sell their stories find themselves outside the organization, and possibly end up with a bullet in the eye' (Parker, 2010: 381). Even more brutal than what was described by private equity specialists as a defining feature of their business; but it expressed much the same principles.

We have suggested that speaking to these founders of private equity in the UK has shone a light on the process of the deliberate creation of a different social context for making and breaking trust, one that borrowed heavily from the past, but that simultaneously also attempted to transform that past. So while these PE practitioners did not wantonly abandon ideals of close social relations, long-term commitment and principles of integrity and trustworthiness, at the same time, in extolling the need for harsh and uncompromising punishment for any failure, they were also thumbing their noses at other aspects of 'tradition'. Private equity in the UK as we see it today is the result.

\section{Notes}

1 Of course, the collapse of Southern Cross is not simply a result of the sale and leaseback by private equity owners. Falling occupation rates and poor management were important contributory factors but the episode has been notable for bringing private equity practices back into public view.

2 A selection of diverse approaches includes Deleuze and Guattari (1988); Hardt and Negri (2000); Harvey (2003); Holmes (2000); Mandel and Humphrey (2002).

3 See, for example, Gregory (1982 and 1997); Humphrey and Hugh-Jones (1992); Mauss (1990); Polanyi (1985 [1944]); Weber (1992).

4 The Financial Times (19 July 2007) estimates that, under this regime, tax paid on carried interest was closer to 10 per cent, compared with the 40 per cent higher rate income tax that the PE partners would have paid. For more details about the tax regime in 2007, its origins and some of the controversy, see the House of Commons Treasury Select Committee 10th Report, chapter 6 (House of Commons, 2007).

\section{References}

Aaronovitch, S., (1961), The Ruling Class: A Study of British Finance Capital, London: Lawrence and Wishart. 
Augar, P., (2000), The Death of Gentlemanly Capitalism, London: Penguin.

Augar, P., (2005), The Greed Merchants: How the Investment Banks Played the Free Market Game, London: Penguin.

Barbalet, J., (2009), 'A characterization of trust, and its consequences', Theory and Society, 38: 367-382.

Berezin, M., (2009), 'Exploring emotions and the economy: new contributions from sociological theory', Theory and Society, 38: 335-346.

Coleman, J.S., (1990), Foundations of Social Theory, Cambridge, MA: Harvard University Press.

Cook, K.S., (2001), 'Trust in society', in Cook, K.S. (ed.), Trust in Society, xi-xxviii, New York: Russell Sage Foundation.

Courtney, C. and Thompson, P., (1996), City Lives: The Changing Voices of British Finance, London: Methuen.

Davis, A., (2007), 'The limits of metrological performativity: the case of valuations in the London Stock Exchange', Competition and Change, 10 (1): 3-22.

Deleuze, G. and Guattari, F., (1988), A Thousand Plateaus: Capitalism and Schizophrenia, London: Athlone Press.

Folkman, P., Froud, J., Johal, S. and Williams, K., (2009), 'Private equity: levered on capital or labour?' Journal of Industrial Relations, 51 (4): 517-527.

Froud, J. and Williams, K., (2007), 'Private equity and the culture of value extraction', New Political Economy, 12 (3): 405-420.

Gambetta, D., (1988), Trust: Making and Breaking Co-operative Relations, Oxford: Blackwell.

Gambetta, D., (1993), The Sicilian Mafia: The Business of Private Protection, Cambridge, MA: Harvard University Press.

Gibbons, R., (2001), 'Trust in social structures: Hobbes and Coase meet repeated games', in Cook, K.S. (ed.), Trust in Society, 332-353, New York: Russell Sage Foundation.

Gregory, C.A., (1982), Gifts and Commodities (Studies in Political Economy), London, New York: Academic Press.

Gregory, C.A., (1997), Savage Money: The Anthropology and Politics of Commodity Exchange (Studies in Anthropology and History; v. 21), Amsterdam, London: Harwood Academic.

Hall, S., (2009), 'Financialised elites and the changing nature of finance capitalism: investment bankers in London's financial district', Competition and Change 13 (2): 173-189.

Hardin, R., (2001), 'Conceptions and explanations of trust', in Cook, K.S. (ed.), Trust in Society, 1-39, New York: Russell Sage Foundation.

Hardt, M. and Negri, A., (2000), Empire, Cambridge, MA: Harvard University Press.

Harvey, D., (2003), The New Imperialism, Oxford: Oxford University Press.

Heimer, C.A., (2001), 'Solving the problem of trust', in Cook, K.S. (ed.), Trust in Society, 40-88, New York: Russell Sage Foundation.

Herzfeld, M., (1997), Cultural Intimacy: Social Poetics in the Nation-State, London: Routledge.

Holmes, D.R., (2000), Integral Europe: Fast-capitalism, Multiculturalism, Neofascism, Princeton, NJ: Princeton University Press.

House of Commons Treasury Committee, (2007), Private Equity. Tenth Report, session 2006-2007, London: The Stationary Office.

Humphrey, C. and Hugh-Jones, S. (eds), (1992), Barter, Exchange and Value: An Anthropological Approach, Cambridge: Cambridge University Press.

Hutton, W., (1995), The State We're In, London: Vintage.

IFSL (International Financial Services London), (2008), Private Equity, London: IFSL.

Kramer, R.M. and Tyler, T.R., (1995), Trust in Organizations, New York: Russell Sage Foundation. Kynaston, D., (2001), The City of London: Club no More, 1945-2000 v. 4, London: Pimlico.

Latour, B., (1987), Science in Action: How to Follow Scientists and Engineers through Society, Milton Keynes: Open University Press.

Luhmann, N., (1979), 'Trust: a mechanism for the reduction of social complexity', in Luhmann, N. (ed.), Trust and Power, New York: Wiley. 
Mandel, R.E. and Humphrey, C. (eds), (2002), Markets and Moralities: Ethnographies of Postsocialism, Oxford: Berg.

Mauss, M., (1990), The Gift: The Form and Reason for Exchange in Archaic Societies (trans. W.D. Halls), London: Routledge.

Parker, M., (2010), “"Tony Soprano on management”: the Mafia and organizational excellence', Journal of Cultural Economy, 3: 379-392.

Peston, R., (2008), Who Runs Britain? How the Super-rich Are Changing our Lives, London: Hodder and Stoughton.

Pixley, J. (2004), Emotions in Finance. Distrust and Uncertainty in Global Markets. Cambridge: Cambridge University Press.

Polanyi, K., (1985 [1944]), The Great Transformation, Boston, MA: Beacon Press.

Sampson, A., (1965), Anatomy of Britain Today, London: Hodder and Stoughton.

Sampson, A., (2004), Who Runs this Place? The Anatomy of Britain in the 21st Century, London: John Murray.

Sandelson, V., (1959), 'The confidence trick', in Thomas, H. (ed.), The Establishment, London: Anthony Blond.

Sennett, R., (2006), The Culture of the New Capitalism (The Castle lectures in ethics, politics, and economics), New Haven, CT: Yale University Press.

Shapiro, S.P., (1987), 'The social control of impersonal trust', American Journal of Sociology, 93 (3): 623-658.

Tett, G., (2009), Fool's Gold: How Unrestrained Greed Corrupted a Dream, Shattered Global Markets and Unleashed a Catastrophe, London: Little Brown.

Thompson, P., (1997a), 'The pyrrhic victory of gentlemanly capitalism: the financial elite of the City of London, 1945-90, Part 1', Journal of Contemporary History, 32 (3): 283-304.

Thompson, P., (1997b), 'The pyrrhic victory of gentlemanly capitalism: the financial elite of the City of London, 1945-90, Part 2', Journal of Contemporary History, 32 (4): 427-440.

Weber, M., (1992), The Protestant Ethic and the Spirit of Capitalism (trans. T. Parsons), London: Routledge. 